\title{
Terminologia DeCS e as novas regras ortográficas da língua portuguesa: orientações para uma atualização ${ }^{1}$
}

\author{
DeCS terminology and the new rules on orthography of \\ Portuguese language: guidelines for an update
}

\begin{abstract}
Teresa Avalos Pereira', Edna Frasson de Souza Montero II
${ }^{\text {I }}$ Mestranda do Programa de Pós-Graduação em Gestão e Informática em Saúde, Universidade Federal de São Paulo - UNIFESP, São Paulo - SP, Brasil. Membro do Núcleo de Comunicação Científica em Ciências da Saúde (NCCCS), UNIFESP. Concepção, conteúdo intelectual e científico, redação do manuscrito.

${ }^{\text {II }} \mathrm{PhD}$, Professora Associada da Disciplina de Cirurgia Geral e do Trauma, Departamento de Cirurgia da Universidade de São Paulo - USP, São Paulo - SP, Brasil. Vice-Líder do Grupo de Pesquisa-CNPq, Núcleo de Comunicação Científica em Ciências da Saúde - NCCCS, UNIFESP. Concepção, conteúdo intelectual e científico, revisão crítica.
\end{abstract}

\section{RESUMO}

OBJETIVO: Destacar as mudanças ortográficas a serem utilizadas como referencial básico por profissionais, pesquisadores, médicos, professores, alunos e usuários, que estão diretamente vinculados e exercendo atividades nos serviços de saúde em geral, visando à aplicação da ortografia correta na recuperação e produção de seus trabalhos científicos.

MÉTODOS: Para a coleta dos dados, foram mostrados alguns exemplos de termos DeCS (Descritores em Ciências da Saúde), analisados conforme a ortografia vigente e comparados com o Vocabulário Ortográfico da Língua Portuguesa (VOLP).

RESULTADOS: Foram selecionados e listados exemplos de descritores e/ou termos relacionados às Ciências da Saúde, os quais foram comparados com as respectivas regras do Acordo Ortográfico da Língua Portuguesa e divididos em três itens: acentuação gráfica, o não uso do trema e suas exceções e o uso ou não do hífen.

CONCLUSÃO: Este estudo indica algumas diretrizes para as alterações dos descritores de acordo com a Nova Ortografia da Língua Portuguesa, contribuindo para a eficiência na descrição dos conteúdos dos documentos e na sua recuperação.

Descritores: Terminologia como Assunto. Descritores em Ciências da Saúde. Estudos de Linguagem. Redação/normas.

\section{ABSTRACT}

PURPOSE: To indicate orthographic changes to be used as a basic reference for professionals, researchers, doctors, teachers, students and users, which are directly linked and performing activities in health services in general, aimed at implementing the correct orthography in recovery and production of their scientific studies.

METHODS: For data collection, were shown some examples of terminology DeCS (Descriptors in Health Science) analyzed according to the current spelling and compared with the Orthographic Vocabulary of Portuguese Language (VOLP).

RESULTS: It was select and listed examples of key words and/or terms related to Health Sciences, which was compared to the respective rules of the Orthographic Agreement of Portuguese Language, and divided into three items: graphical accentuation, the non use of dieresis and exceptions and, the use of hyphen.

CONCLUSION: This study show some guidelines for the orthographic alterations of the terms used by scientific community, according the new orthographic rules, contributing for the efficiency in the description of the documents and consequently in their recovery.

Key words: Terminology as Topic. Medical Subject Headings. Language Arts. Writing/standards 


\section{Introdução}

Toda ciência necessita terminologia própria que se adeque às suas necessidades de comunicação e expressão. Os conceitos de determinada área do conhecimento são representados através de termos. O termo é o objeto de estudo da Terminologia.

Vocabulários estruturados são necessários para descrever, organizar e prover acesso à informação. Isso permite ao usuário recuperar a informação com o termo exato que foi escolhido para descrever o conteúdo do documento científico. Esses vocabulários controlados "funcionam como mapas que guiam os pesquisadores até a informação", por isso a sua grande importância. ${ }^{1}$

O DeCS (Descritores em Ciências da Saúde) é um vocabulário controlado trilíngue, criado em 1982 pela BIREME/ OPAS/OMS - Centro Latino-americano e do Caribe de Informação em Ciências da Saúde. Foi desenvolvido a partir do MeSH (Medical Subject Headings), que são os cabeçalhos ou descritores de assunto produzido pela NLM (U.S. National Library of Medicine), responsável pela base de dados MEDLINE, que disponibiliza de 20 milhões de citações bibliográficas da Literatura Científica e Técnica Internacional na área da Saúde. ${ }^{2}$

O vocabulário DeCS contém a terminologia padrão em Ciências da Saúde em português, espanhol e inglês, usado na indexação de artigos de revistas científicas, livros, anais de congressos, capítulos de livros, teses e outros tipos de materiais na pesquisa e recuperação de assuntos na base de dados LILACS (Literatura Latino-Americana e do Caribe em Ciências da Saúde), assim como em outras fontes de informação na Biblioteca Virtual em Saúde (BVS).

Sendo o DeCS o vocabulário utilizado que serve como linguagem única para indexação, recuperação e navegação em todas as fontes de informação em 37 países na América Latina e do Caribe, é bastante pertinente para que se faça esse estudo.

A atualização que anualmente o MeSH realiza e também as mudanças que ocorrem nas demais categorias DeCS, criam a necessidade de revisão e atualização. Os conceitos que compõem o DeCS são organizados em uma estrutura hierárquica, em 17 categorias, fundamentado na divisão do conhecimento em classes e subclasses decimais e possui atualização anual. ${ }^{3}$ Permite a execução de pesquisa em termos mais amplos ou mais específicos ou todos os termos que pertençam a uma mesma estrutura hierárquica.

A proposta deste estudo surgiu a partir da necessidade de aperfeiçoamento e atualização de profissionais, pesquisadores, médicos, professores, alunos e usuários que estão diretamente vinculados e exercendo atividades nos serviços de saúde em geral, quanto às Novas Regras da Ortografia da Língua Portuguesa vigentes.

Em 30 de setembro de 2008 entrou em vigor o Decreto 6.583/08, assinado pelo Presidente Luiz Inácio Lula da Silva, promulgando o Acordo Ortográfico da Língua Portuguesa, estabelecido entre os países que têm a língua portuguesa como idioma oficial (Angola, Brasil, Cabo Verde, Guiné-Bissau, Moçambique, Portugal, São Tomé e Príncipe e Timor Leste), produzindo efeitos a partir de $1^{\circ}$ de janeiro de 2009 , havendo um período de transição entre $1^{\circ}$ de janeiro de 2009 e 31 de dezembro de 2012.

A dúvida dos mestrandos e doutorandos e demais pesquisadores, no momento da dissertação de seus trabalhos é se o texto está de acordo com a norma culta, se não existem erros de português e, principalmente, se a ortografia está correta. A problemática agora não é somente com a recuperação da informação em saúde, se está sendo bem feita, mas também como escrever bem e corretamente. A insegurança é tão grande que muitas vezes o pesquisador coloca sua tese nas mãos de um professor de português para fazer a revisão do texto.

O presente estudo tem como objetivo destacar termos em Ciências da Saúde quanto às mudanças ortográficas, focando na acentuação das palavras e no uso ou não do hífen, visando à aplicação correta dos descritores conforme o Acordo Ortográfico da Língua Portuguesa, na recuperação e produção de trabalhos científicos de profissionais, pesquisadores, médicos, professores e alunos da área da saúde em geral.

\section{Métodos}

Foi realizada breve síntese das modificações efetuadas no idioma português do Brasil e que tivessem interesse à vida acadêmica. Para a coleta dos dados, foram listados alguns exemplos de termos do DeCS (Descritores em Ciências da Saúde) escritos com a ortografia anterior e na contralateral os mesmos termos de acordo com as novas regras do Acordo. As principais regras apresentadas foram com relação às palavras que não são mais acentuadas e no uso ou não do hífen de termos compostos por prefixos ou falsos prefixos. Foi consultada a terminologia DeCS e comparada tanto com o Acordo Oficial como também com o VOLP, que é a nossa expressão máxima da ortografia oficial ${ }^{4}$

\section{Resultados}

A seguir, estão selecionados e listados nos quadros exemplos de descritores e/ou termos de Ciências da Saúde, comparados com as respectivas regras do Acordo Ortográfico da 
Língua Portuguesa e divididos em três itens: acentuação gráfica, o não uso do trema e suas exceções e o uso ou não do hífen ${ }^{5,6}$.

Da acentuação gráfica das palavras paroxítonas e acento circunflexo.

Os ditongos abertos ("ei” e "oi”) não são mais acentuados em palavras paroxítonas. Prescinde-se igualmente do acento circunflexo para assinalar a vogal tónica/tônica fechada com a grafia “o” em palavras paroxítonas (Quadro 1)

QUADRO 1: Exemplos de alguns ditongos e acento circunflexo usuais na prática médica

DITONGO

\begin{tabular}{|c|c|}
\hline Como era & Como fica \\
\hline amenorréia & amenorreia \\
\hline amilóide & amiloide \\
\hline apnéia & apneia \\
\hline cefaléia & cefaleia \\
\hline corióide & corioide \\
\hline corticosteróides & corticosteroides \\
\hline diarréia & diarreia \\
\hline dispneia & dispneia \\
\hline esteróides & esteroides \\
\hline glândula tireóide & traqueia \\
\hline traquéia & ureia \\
\hline uréia & Como fica \\
\hline \multicolumn{2}{|c|}{ ACENTO CICUNFLEXO } \\
\hline Como era & Enjoo devido ao movimento em voo \\
\hline Enjôo devido ao movimento em vôo & espacial \\
\hline espacial &
\end{tabular}

\section{Do trema}

O trema, sinal de diérese, é inteiramente suprimido. Conserva-se, no entanto, em casos de nomes próprios e seus derivados, por exemplo: Müller, mülleriano (Quadro 2).

QUADRO 2: Exemplos da extinção do trema

\begin{tabular}{|c|c|}
\hline Como era & Como fica \\
\hline conseqüência & consequência \\
\hline freqüência & frequência \\
\hline sangüíneo & sanguíneo \\
\hline seqüência & sequência \\
\hline ungüentos & unguentos \\
\hline
\end{tabular}

\section{Do hifen}

Os termos médicos, em sua grande maioria, são formados a partir de radicais, prefixos e sufixos gregos e latinos. Talvez seja este item o de maior dificuldade em se aplicar corretamente em função das variadas circunstâncias em que ele se encontra previsto. A intenção dos autores é sumarizar, nos quadros seguintes, as ocasiões em que ele é requerido ou não na prática da grande área da saúde.

A seguir citam-se as principais regras sumarizadas do seu manuseio

a) O hífen não é mais usado em palavras formadas de prefixos (ou falsos prefixos) terminados em vogal com palavras iniciadas por "r" ou "s", sendo que essas devem ser dobradas (Quadro 3).

b) Ele não é mais utilizado em palavras formadas de prefixos (ou falsos prefixos) terminados em vogal em palavras iniciadas com outra consoante que não seja o "r" ou "s" (Quadro 4).

c) A regra não se aplica quando a palavra seguinte iniciar por "h" (Quadro 5).

d) O hífen não é mais utilizado em palavras formadas de prefixos (ou falsos prefixos) terminados em vogal com palavras iniciadas por outra vogal (Quadro 6).

e) Utiliza-se hífen quando a palavra é formada por um prefixo (ou falso prefixo) terminado em vogal e a outra palavra é iniciada pela mesma vogal (Quadro 7).

f) Não se usa o hífen quando o prefixo (ou falso prefixo) termina por consoante e a outra palavra começa com vogal (Quadro 8).

g) Utiliza-se o hífen quando o prefixo termina em consoante e a outra palavra inicia pela mesma consoante (Quadro 9).

h) O uso do hífen permanece em palavras formadas por prefixos "circum" e "pan" + palavras iniciadas em vogal, "m" ou "n" (Quadro 10).

i) $\mathrm{O}$ prefixo $\mathrm{CO}$ aglutina-se com o segundo elemento, mesmo quando ele inicia por “o” (Quadro 11).

j) O mesmo acontece com o prefixo "re", havendo a supressão do " $h$ " do segundo elemento (Quadro 12).

k) O uso do hífen permanece em palavras formadas com prefixos “além”, “aquém”, "recém”, “sem”, “pré”, "pró” e "pós" com palavras que têm significado próprio. Exceção: Nos casos em que o prefixo "pré" se apresenta como átono, isto é, sem autonomia fonética - razão pela qual precisa se apoiar na sílaba seguinte, ele não é acompanhado do uso do hífen e, obviamente, não recebe acento gráfico. (Quadro 13).

1) As palavras constituídas por temas nominais gregos e latinos 
continuam sem hífen, mesmo que contenham mais de dois elementos (Quadro 14).

m) Não se usa hífen na formação de palavras com "não" e "quase" (Quadro 15).

n) Usa-se o hífen diante de palavra composta começada por "b", "d" ou "r" (Quadro 16).

o) Com o prefixo "sub", só haverá hífen diante de palavras iniciadas por b, h e r (Quadro 17).

p) Atenção especial deve ser dada ao uso do hífen que permanece em palavras compostas que não contenham elemento de ligação e constituem unidade sintagmática e semântica, mantendo o acento próprio, bem como naquelas que designam espécies botânicas e zoológicas (Quadro 18).

q) Emprega-se o hífen nos compostos com os advérbios "bem" e "mal", quando a palavra seguinte começar por "h" ou vogal (Quadro 19).

r) Quando "mal” significa doença, usa-se o hífen se não houver elemento de ligação (Quadro 20).

s) Se houver elemento de ligação, escreve-se sem o hífen (Quadro 21).

QUADRO 3: Palavras iniciadas por prefixos ou falsos prefixos com " $r$ " ou "s"

\begin{tabular}{|c|c|}
\hline Como era & Como fica \\
\hline anti-retroviral & antirretroviral \\
anti-reumáticos & antirreumáticos \\
anti-sepsia & antissepsia \\
extra-sensorial & extrassensorial \\
extra-sístole & extrassístole \\
pseudo-raiva & pseudorraiva \\
supra-renal & suprarrenal \\
\hline
\end{tabular}

QUADRO 4: Palavras não começadas com "r" ou "s"

\begin{tabular}{|c|c|}
\hline Como era & Como fica \\
\hline anti-fúngico & antifúngico \\
anti-microbiana & antimicrobiana \\
anti-neoplásico & antineoplásico \\
anti-plaquetas & antiplaquetas \\
semi-permanente & semipermanente \\
\hline
\end{tabular}

QUADRO 5: Manutenção do hífen nas palavras começadas com " $h$ "

\begin{tabular}{|c|c|}
\hline anti-helmíntico & anti-hemorrágico \\
\hline anti-higiênico & anti-histamínico \\
\hline auto-hemoterapia & auto-hipnose \\
\hline poli-hidratação & sub-hepático \\
\hline
\end{tabular}

QUADRO 6: Palavra terminada em vogal com outra iniciada por outra vogal não usa hífen

\begin{tabular}{|c|c|}
\hline Como era & Como fica \\
\hline anti-andrógenos & antiandrógenos \\
agentes anti-obesidade & agentes antiobesidades \\
auto-administração & autoadministração \\
auto-análise & autoanálise \\
auto-anticorpos & autoanticorpos \\
auto-antígenos & autoantígenos \\
auto-avaliação & autoavaliação \\
auto-exame & autoexame \\
auto-imagem & autoimagem \\
doenças auto-imunes & doenças autoimunes \\
contra-indicação & contraindicação \\
membranas extra-embrionárias & membranas extraembrionárias \\
infra-estrutura sanitária & infraestrutura sanitária \\
intra-oculares & intraoculares \\
intra-operatório & intraoperatório \\
intra-uterina & intrauterina \\
pseudo-artrose & pseudoartrose \\
pseudo-edema & pseudoedema \\
semi-aberto & semiaberto \\
zona semi-árida & zona semiárida \\
\hline
\end{tabular}

QUADRO 7: Usa-se hífen em palavras terminadas em vogal e a outra palavra iniciada com a mesma vogal

\begin{tabular}{|c|c|}
\hline Como era & Como fica \\
\hline antiinfecciosos & anti-infecciosos \\
antiinflamatórios & anti-inflamatórios \\
anticorpos antiinsulina & anticorpos anti-insulina \\
microondas & micro-ondas \\
microorganismos & micro-organismos \\
\hline
\end{tabular}

QUADRO 8: Não se usa hífen em palavras com o prefixo que termina com consoante e a outra palavra começa com vogal superestrutura

QUADRO 9: Usa-se hífen em prefixos terminados em consoante e a outra palavra inicia com a mesma consoante

\begin{tabular}{|c|c|}
\hline hiper-raquítico & hiper-reflexia \\
\hline inter-relação & super-resistente \\
\hline
\end{tabular}

QUADRO 10: Usa-se hífen em prefixos "circum" e "pan" quando a outra palavra inicia em vogal, "m" ou "n"

\begin{tabular}{|c|c|}
\hline pan-mielopatia & pan-oftalmia \\
\hline pan-osteíte & circum-meridiano \\
\hline
\end{tabular}

QUADRO 11: Não se usa hífen em palavras com o prefixo "CO”

\begin{tabular}{|c|c|}
\hline coautor & coarctação \\
\hline coenzima & coestimulação \\
\hline coexistente & comorbidade \\
\hline cofator & coocupante \\
\hline coorientação & cosseguros \\
\hline
\end{tabular}


QUADRO 12: Não se usa hífen em palavras com o prefixo "RE" e suprime-se o "H" na associação com a outra palavra, quando houver

$$
\text { reidratar }
$$
reumanizar

QUADRO 13: Mantém-se o hífen em palavras compostas com “ALÉM”, “AQUÉM", "RECÉM”, “SEM”, "PRÉ”, "PRÓ” E "PÓS”. Exceção: Nos casos em que o prefixo "pré" se apresenta como átono, isto é, sem autonomia fonética

\begin{tabular}{|c|c|}
\hline pós-graduação & pós-operatório \\
\hline pós-parto & pós-prandial \\
\hline pré-anestésico & pré-clínico \\
\hline pré-coma & pré-diabetes \\
\hline pré-eclâmpsia & pré-existente \\
\hline pré-ganglionar & pré-hipófise \\
\hline pré-medicação & pré-menstrual \\
\hline pré-natal & pré-operatório \\
\hline pré-pilórico & pré-senil \\
\hline recém-admitido & recém-nascido \\
\hline Exceção: precondicionamento, preaquecer, preconcebido \\
\hline
\end{tabular}

QUADRO 14: Não se usa hífen em palavras compostas com nominais gregos e latinos

\begin{tabular}{|c|c|}
\hline adenoipófise & gastroenteroanastomose \\
\hline anatomopatológico & laringotraqueobronquite \\
\hline angiocinecoronariografia & neuropsiquiátrico \\
\hline esofagogasteoduodenoscopia & radioimunoensaio \\
\hline
\end{tabular}

QUADRO 15: Palavras precedidas por "não" e "quase" não levam hífen

\begin{tabular}{|c|c|}
\hline (Acordo de) não agressão & não elástico \\
\hline (Isto é um) quase delito & quase elástico \\
\hline
\end{tabular}

QUADRO 16: Existe hífen em palavras compostas iniciadas por "b", "d" ou "r"

\begin{tabular}{|c|c|}
\hline ab-rogar & ad-digital \\
\hline ad-renal & \\
\hline
\end{tabular}

QUADRO 17: “sub” exige hífen somente em palavras iniciadas por "b", "h" ou "r"

\begin{tabular}{|c|c|}
\hline subalimentação & sub-braquial \\
\hline sublingual & sub-hepático \\
\hline subunidade & sub-retiniano \\
\hline
\end{tabular}

QUADRO 18: hífen continua em palavras compostas que não possuem elemento de ligação

\begin{tabular}{|c|c|}
\hline conta-gotas & dígito-pressão \\
\hline duplo(s)-cego(s) & médico-chefe \\
\hline médico-cirurgião & médico-hospitalar \\
\hline médico-legal & médico-legista \\
\hline médico-residente & médico-veterinário \\
\hline meia(s)-vida(s) & ponto-gatilho \\
\hline
\end{tabular}

QUADRO 19: "BEM" e "MAL" exigem hífen quando a palavra seguinte inicia por vogal ou " $\mathrm{H}$ "

\begin{tabular}{|c|c|}
\hline bem-estar & mal-estar \\
\hline bem-entendido & mal-entendido \\
\hline mal-humorado & \\
\hline
\end{tabular}

QUADRO 20: Sem elemento de ligação, o termo "mal" usa hífen quando se refere à doença

\begin{tabular}{|c|c|}
\hline mal-francês & mal-caduco \\
\hline
\end{tabular}

QUADRO 21: Escreve-se sem o hífen

\begin{tabular}{|c|c|}
\hline mal de Alzheimer & mal de Lázaro \\
\hline mal de sete dias & \\
\hline
\end{tabular}

\section{Discussão}

Ao iniciar este estudo, foram selecionadas as principais regras da Nova Ortografia, relacionando-as com alguns termos do DeCS que necessitam de mudanças e outros que ainda deixaram dúvidas quanto à nova ortografia.

Usar a terminologia correta não é somente uma questão semântica ou sem importância, para se falar ou escrever construtivamente, sobre assuntos de cunho humano. É especialmente importante quando se aborda assuntos na área da saúde. ${ }^{7}$ Para que se pudesse obter recuperação efetiva de estudos e pesquisas em artigos científicos e outros documentos, foi preciso a criação de descritores, que representam as palavras-chave.

$\mathrm{Na}$ área de saúde é importante ressaltar a diferença entre palavra-chave e descritor. A primeira não obedece a nenhuma estrutura, é aleatória e retirada de textos de linguagem livre. Para uma palavra-chave tornar-se um descritor, ela tem que passar por rígido controle de sinônimos, significado e importância na árvore de determinado assunto. ${ }^{8}$

A necessidade de linguagem comum é consenso, e, para tanto, requer habilidades para que se estruture e propague uma boa nomenclatura, principalmente pela quantidade de diferentes atores e interesses envolvidos. A área da saúde tem linguagem de difícil entendimento pelo leigo. Cada termo médico caracteriza um objeto, sugere uma ação, representa uma ideia ou define um procedimento, cujo significado está na própria palavra. O uso dos prefixos ou radicais gregos e latinos, comuns a vários termos, permite expressar em poucas palavras fatos e conceitos que, de outra maneira, demandariam locuções e frases extensas. ${ }^{9}$

Em seu artigo, Brandau et al. ${ }^{8}$ reforçam sobre a importância do uso correto dos descritores nos artigos científicos, pois, se eles não estiverem de acordo com a nomenclatura, os artigos correm o risco de não serem encontrados e, portanto, nem citados. "Isso 
traz prejuízo grande, visto que quanto maior o número de citações, mais valorizada é a revista e, por consequência, aqueles que têm seus artigos nas suas páginas". ${ }^{8}$

Segundo Timi ${ }^{10}$ ao se indicar corretamente os descritores de assunto em um trabalho, o autor contribui na promoção do conhecimento científico, proporcionando aos pesquisadores mais facilidade na recuperação da informação. "Entretanto, um artigo publicado com descritores mal selecionados ou não caracterizadores do assunto é igual a uma estrela anônima perdida no firmamento, que jamais será referenciada nem pelos cientistas nem pelos poetas". ${ }^{10}$

A apresentação de termos comumente utilizados pela comunidade científica da área da saúde, correlacionandoos às novas regras ortográficas, propõe-se a contribuir com a conscientização dessa comunidade e estimular o uso adequado na redação científica.

\section{Conclusão}

Este estudo indica algumas diretrizes para as alterações dos descritores de acordo com a Nova Ortografia da Língua Portuguesa, contribuindo para a eficiência na descrição dos conteúdos dos documentos e na sua recuperação.

\section{Referências}

1. Castro E. Terminologia, palavras-chave, descritores em saúde: qual a sua utilidade? Folha Méd. 2001;120(1):40-50.

2. DeCS: Descritores em Ciências da Saúde [Internet]. São Paulo: Bireme. 1982 - [citado 2010 Jan 1]. Disponível em: http://decs.bvs. br

3. Pellizzon RF. Pesquisa na área da saúde: 1. Base de dados DeCS (Descritores em Ciências da Saúde). Acta Cir Bras. 2004;19(2):15363.

4. Academia Brasileira de Letras. Vocabulário ortográfico da língua portuguesa (VOLP). 5a ed. São Paulo: Global; 2009.

5. Bechara E. O que muda com o novo Acordo Ortográfico. Rio de Janeiro: Nova Fronteira; 2008.

6. Instituto Antônio Houaiss. Escrevendo pela nova ortografia: como usar as regras do novo acordo ortográfico da língua portuguesa. São Paulo: Publifolha; 2008.

7. Sassaki RK. Terminologia sobre deficiência na era da inclusão. In: Vivarta V, coordenador, editores. Mídia e deficiência. Brasília: Andi/ Fundação Banco do Brasil; 2003. p. 160-5.

8. Brandau R, Monteiro R, Braile DM. Importância do uso correto dos descritores nos artigos científicos. Rev Bras Cir Cardiovasc. 2005;20(1):VII-IX.

9. Rezende JM. A terminologia médica após o novo Acordo Ortográfico: linguagem médica. Rev Patol Trop. 2009;38(1):67-9.

10. Timi JR. A importância do uso dos descritores nas publicações médicas. J Vasc Bras. 2005;4(2):114-5.

\section{Correspondência:}

Teresa Avalos Pereira,

Biblioteca Central da UNIFESP

Rua Botucatu, 862 - São Paulo - SP

Tel.: (11) 5576-4562 - VOIP - 1700

teresa.bc@epm.br

Conflito de interesse: nenhum

Fonte de financiamento: nenhum

${ }^{1}$ Pesquisa realizada no Núcleo de Comunicação Científica em Ciências da Saúde-NCCCS, Universidade Federal de São Paulo-SP, Brasil. 